\title{
UK edges slowly towards first trials of an AIDS vaccine
}

\section{London}

Six months after initiating a directed programme of research on AIDS (acquired immune deficiency syndrome), the UK Medical Research Council (MRC) is confident that its first vaccine trials will begin within a year. Research into new drugs will take longer to bear fruit.

The $£ 2.5$ million earmarked for the first year of the programme has now been committed and two major grants, each of $£ 1$ million over five years, have been awarded. One grant is for Professor Robin Weiss of the Institute of Cancer Research to study the biology of human immunodeficiency virus (HIV) and to carry out HIV neutralization tests as a service. The other grant is for Professor William Jarrett's work at Glasgow University on viruses and vaccines.

Jarrett favours subunit vaccines, in which the essential component is a purified viral protein, rather than vaccines based on vaccinia viruses carrying an HIV gene. Monkey trials of such vaccines have all failed, he says, and his own work on the use of adenovirus in place of vaccinia virus has encountered a serious obstacle. Moreover, he would now be concerned by the prospect of any vaccine that led to the continued synthesis of viral envelope protein in view of its possible toxicity

Jarrett and his brother Oswald have developed a highly effective vaccine against feline leukaemia virus, which is a retrovirus like HIV, and have already tested a similar HIV vaccine in monkeys. In the vaccines a protein from the envelope that surrounds the virus is incorporated into an 'iscom' (immune stimulating complex).

Iscom technology, developed by Bror Morein of the Swedish University of Agricultural Sciences in Uppsala, attaches the viral protein by hydrophobic interaction to a particle-like matrix of the glycoside Quil A, which is extracted from the bark of Amazonian oak trees. Iscom preparations induce a greater immune response than most alternative vaccine preparations. (The latest potential rival is based on virus-like particles produced by yeast - see Nature 329, 68; 1987.)

Jarrett and Sir James Gowans, who retires as head of the Medical Research Council this month, are both confident that the way will be cleared to carry out initial human tests of an HIV-iscom vaccine within the next year. Tests on monkeys, carried out in conjunction with the US National Cancer Institute, have shown that HIV-iscom preparations are both safe and good immunogens. The favoured protein for the first human tests is the gp120 envelope protein of HIV, the major subunit of the gp160 protein that will be used in the first US vaccine test (Nature 328, 747; 1987).

The main hurdles to an early UK trial are now bureaucratic. General guidelines, an approved protocol, ethical issues and the choice of volunteers have all to be decided. Both Jarrett and Dr Geoffrey Schild, who is to succeed Gowans as the director of the MRC's AIDS programme, emphasize that they are determined to avoid vaccine trials that are carried out by "enthusiasts" on a small number of people and using unstandardized protocols. One would be little the wiser from such trials, said Jarrett. The task of standardization will fall to Schild, wearing his other hat as director of the National Institute for Biological Standards and Control.

On the antiviral front, the MRC programme has been less immediately productive. Its director, Dr Max Perutz, says that one aim is to arouse the interest of academic chemists in new approaches to the synthesis of inhibitors of HIV's reverse transcriptase enzyme. As befits his own experience, Perutz is also keen to support attempts to determine the crystal structure of HIV proteins so as to allow more rational drug design. Projects to crystallize HIV reverse transcriptase, proteinase, envelope and tatIII proteins are being supported in Cambridge, London and York.
Peter Newmark

\section{Safety issues raised by worker's infection with AIDS virus}

Washington

A LABORATORY worker who became infected with human immunodeficiency virus (HIV), the virus causing AIDS (acquired immune deficiency syndrome), may not have followed accepted safety procedures while handling highly concentrated samples of the virus (see Nature 329, 92; 1987). That conclusion follows a telephone interview between the infected worker - whose identity is being withheld to protect confidentiality agreements and the leader of a safety team investigating the circumstances surrounding the infection first detected 18 months ago.

Emmett Barkley, former director of the division of laboratory safety at the National Institutes of Health (NIH) and leader of the safety team says the worker could not identify an overt event such as a broken vessel or needle stick that could have resulted in transmission of the virus. But Barkley says his conversation revealed several possible "inapparent exposures". The worker, whose job included concentrating the virus in a centrifuge using a density gradient, reported that the seals around the centrifuge rotor had occasionally leaked. The worker handled the virus at times when skin lesions, cuts and abrasions were present, but always wore gloves while handling the virus. But Barkley says gloves may tear or have pin holes without the wearer being aware of it.

The infected worker did not work on campus at NIH, but instead was employed by an NIH contractor. Peter Fischinger, deputy director of the National Cancer Institute, says he believes that NIH safety procedures are adequate, but agrees that the incident raises questions about whether workers are adequately trained in procedures. He also says some modifica- tions of procedures for handling the virus may be made. NIH officials are convinced that the infection did not result from inhalation of an aerosol.

Barkley says $\mathrm{NIH}$ rules do not require that HIV be handled in P3 facilities. (These high-level containment facilities are now officially known as BL 3 facilities, for biosafety level 3 .) Instead, they allow the virus to be handled in BL2 facilities using BL3 techniques such as wearing gloves and working in a laminar flow hood.

Some at NIH have criticized the institute's handling of the event. Fischinger says the Centers for Disease Control (CDC) in Atlanta were notified of the occupational exposure after the virus was isolated in the infected individual and shown by restriction mapping to be essentially identical to the one being handled in the laboratory. But that determination was made only last month, more than a year after the individual had shown evidence of antibodies to HIV.

NIH director James Wyngaarden admits the delay in informing CDC may have been a mistake, but says it was caused in part by the difficulty in isolating the virus from the infected worker.

Wyngaarden says nine unsuccessful attempts to find the virus in the worker's blood made researchers question whether the antibody testing might not have been falsely positive for the presence of virus. Only after investigators tried a test developed by Robert Gallo was the virus successfully grown.

NIH safety inspectors are now in the process of visiting all facilities around the country where concentrated quantities of HIV are produced. This includes companies making the HIV-antibody test kits. Joseph Palca 